\title{
LEARNING THROUGH WHATSAPP DURING THE COVID-19 PANDEMIC: A CASE STUDY
}

\author{
NOUR MHEIDLY \\ GEISEL GARCÍA GRAÑA \\ SALLY SAMY TAYIE
}

\begin{abstract}
The COVID-19 pandemic forced lockdowns that severely affected the educational sector. The necessary shift to online learning was hindered in countries that lack communication technologies. In addition, the inadequate media and information literacy among educators and students alike exposed deficiencies in disaster preparedness. This resulted in the use of commonly used applications, such as WhatsApp, as a learning platform. We hereby present the learning experience of a mathematics class of the 10th grade through WhatsApp in a Lebanese public school. After analysis, we assess the initiative using the Rubric for eLearning Tool Evaluation. Although WhatsApp, as a learning tool, was functional, accessible, and technically effective, it hindered the learning experience with the lack of social, teaching, and cognitive presence. We offer our insights and recommendations on improving the learning and communication experience as we continue to navigate the current and any future pandemic.
\end{abstract}

Keywords: WhatsApp; COVID-19; Pandemic; Online learning; e-learning; Digital Gap

\section{INTRODUCTION}

The COVID-19 pandemic has changed life patterns and disrupted people's engagement in society (Mheidly et al., 2020a). The contagious nature of the virus led to the closure of borders between countries and imposed total lockdowns to mitigate the virus's effects. Many sectors were affected by the outbreak, and most prominently, the educational one. The pandemic took a heavy toll on education. Many schools and universities closed temporarily. Others stopped the traditional in-person teaching mode and shifted to online learning to ensure the safety of students and faculty members (Dhawan, 2020; Mheidly et al., 2020b). The digital divide and the unequal access to resources that hinder the emergence of knowledge societies posed major challenges in some countries (Bindé, 2005). Privileged groups were equipped with adequate media and information literacy (MIL) and had access to information and communication technologies (ICTs) to integrate into online learning. However, marginalized and lessresourced individuals did not possess similar opportunities (Lee, 2013). People living in poverty in low and middle-income countries were the most affected by the educational shift (Mheidly et al., 2020cd). The lack of digital literacy and resources affected students and teachers, as the educational system was not supported to provide remote learning adequately. This increased the educational inequalities between societies (Masonbrink, 2020).

Lebanon, whose educational system is obsolete and suffers from political and sectarian intrusions (Frayha, 2009), confronted many educational challenges during the COVID-19 pandemic. Rouadi and Anouti (2020) reported that the Lebanese online learning experience during the COVID-19 pandemic was hindered by slow internet connectivity and electric 
outages that contributed to its failure. The socio-economic crisis, compounded by the Beirut Port Ammonium Nitrate explosion, and the need to prioritize funds and resources for basic needs, further hindered the ability of public schools to shift into virtual learning. Primary practical competencies, such as ICTs, and learning skills needed to function and participate effectively in the 21st century were lacking in students (Lee, 2013). Neither the schools nor the students were prepared and trained to work with programs such as Zoom, Microsoft Teams, or Cisco WebEx. Some students did not even own laptops or other digital devices due to low family income.

These challenging circumstances saw public schools resort to WhatsApp as an educational tool during the COVID-19 pandemic. The Facebook-owned application is easy-touse, free, fast, and accessible, as it is present in almost every Lebanese home. It allows users to text, send voice notes, call, or video chat with others from all over the world to drive realtime communication (7). The decision of some schools to use this platform was due to its affordability and simplicity. Almost all students can access it through mobile phones at home, regardless of their economic or literacy status.

\section{RELATED WORKS}

WhatsApp has been used as a learning tool in a variety of settings within the educational sector worldwide. In Nigeria, students who used WhatsApp instructional chat rooms in geography classes had a better academic performance than when taught through conventional ways (Etim et al., 2016). Similarly, in Turkey, the use of mobile phones in learning and memorizing vocabs was more effective than the traditional learning methods (Başoğlu \& Akdemir, 2010). In South Africa, learning through WhatsApp increased the communication and interaction between the students and their teachers and peers; learning through WhatsApp was easier and more fun than the traditional ways (Rambe \& Bere, 2013). In South Korea, mobile learning acted as an opportunity for students to accomplish their learning objectives using real-time communication and interaction (Kim et al., 2014). In Indonesia, using WhatsApp in teaching English as a foreign language improved the students' language skills and developed their writing abilities. WhatsApp features, such as audio and video sharing, texting, taking pictures, and sharing links and documents, were mainly used to support learning activities (Sustani \& Tarmuji, 2016). Indonesian students reported that WhatsApp facilitated learning as it was easy to use, faster in sharing information, promoted problem-solving, and, most importantly, improved their participation and collaboration (Rahaded et al., 2020).

WhatsApp was further shown to have a significant role in English vocabulary learning in Iranian high school students. The teacher compared the two gender-matched groups of students in a controlled trial on the English vocabulary test results. The group of Iranian students who received vocabulary instructions through WhatsApp, four days a week, performed better than the group of students taught vocabularies from their textbook inside the classroom and via traditional methods (Jafari \& Chalak, 2016). In Taiwan, foreign English students preferred using mobile phones to study vocabulary for its features and accessibility (Chen, 2008). In India, WhatsApp helped strengthen relationships between teachers and coordinators, encouraged sharing pedagogical resources, and improved the quality of remote learning (Nedungadi et al., 2017). A cross-sectional survey in India reported that $75 \%$ of business management students felt satisfied with the way WhatsApp made information accessible (Kushwaha \& Jhawar, 2018). Moreover, the use of WhatsApp, among other applications, has been reported to increase the effectiveness of teachers, improve students' academic performance, and reduce absenteeism (Nedungadi et al., 2017) 
During the COVID-19 pandemic, many educational systems used WhatsApp to communicate with students as it was the most affordable and accessible application for teachers and students alike. To combat the challenges of maintaining education during the pandemic, measures such as ensuring access to learning resources and material through digital platforms and social media applications were suggested (Dempsey \& Burke, 2020). In Indonesia, a study was executed to know students' preferences of the most useful applications for learning mathematics during the COVID-19 pandemic. WhatsApp was the second most preferred application for learning mathematics as it recorded a $26.4 \%$ agreeability rate, right after Cisco Webex (52.7\%) (Aziza, 2021). In South Africa, a two-week teaching experience using WhatsApp required teachers and lecturers to collaborate and supervise more persistently than in regular times (Nel, 2020). This collaboration created a good relationship between teachers and faculty members and ensured social presence, effective supervision, and monitoring for the students to enhance their learning experience. However, technical challenges such as the lack of teacher training on navigating applications and the lack of media accessibility were the main challenges when teaching through WhatsApp or other similar platforms (Nel, 2020). A cross-sectional study in Rowanda on teachers' perceptions of using WhatsApp as a learning tool for chemistry classes during the pandemic revealed that the application was effective in promoting engagement, interaction, collaboration, and participation among students (Nsabayezu, 2020). Nevertheless, the lack of smartphones and connectivity problems were hindering this experience (Nsabayezu, 2020).

In this study, we aim to explore the effect of WhatsApp on the educational experience in Lebanon during the COVID-19 pandemic. This work will help us assess the suitability of WhatsApp as a tool that delivers remote learning and distance education and will highlight potential areas for improvement. The findings of this study can be beneficial to Lebanese students, teachers, public schools, educators, and policymakers.

\section{METHODOLOGY}

We conducted a qualitative analysis using the case study approach to present the learning experience of a mathematics class that was primarily taught through WhatsApp in a public school in Beirut, Lebanon.

Data were collected through observations and interviews with several students and the teacher of the class. To analyze and evaluate the described learning experience, we followed the "Rubric eLearning Tool Evaluation" measures. This tool was created by Lauren Anstey and Gavan Watson from Western University, Canada (2018). The tool is composed of criteria that assess an e-learning method in satisfying learners' needs and objectives. It covers eight categories: functionality, accessibility, technical, mobile design, privacy, data protection, and rights, social presence, teaching presence, and cognitive presence (Anstey \& Watson, 2018). Each criterion was assessed by the investigators of this study based on a three-level scale: works well, minor concerns, and serious concerns. Criteria that were not applicable could be designated as such. Results and observations based on this measure were tabulated for assessment. Finally, we conclude with our insights and recommendations to better the learning and communication experience in the days to come (Figure 1). 


\section{Study Methodology}

\section{Case Description}

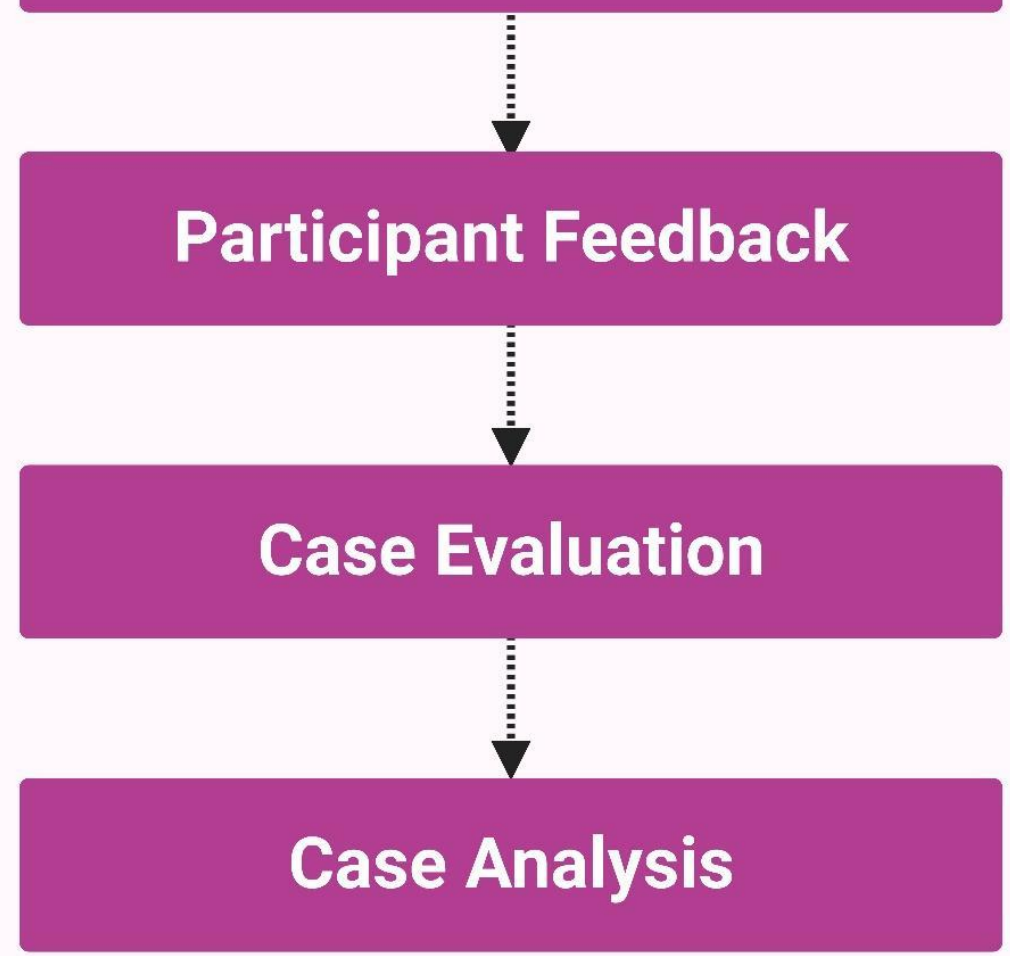

FIGURE 1: Study methodology and workflow of qualitative analysis

\section{CASE DESCRIPTION}

We report the case of one mathematics teacher and 25 students of the $10^{\text {th }}$ grade in a public school in Lebanon. Students were invited to join a WhatsApp group named "Math Session," which was created and moderated by the teacher. The teacher used the school administration data to collect students' phone numbers and add them to the group. Some students did not own cell phones; they used their parent's ones instead. Two days before each session, the teacher sends a text to the group determining the upcoming lesson's name, the date, and the time. Math sessions were taught three times a week, with an average duration of 80 minutes per session. Students were able to communicate with their teacher privately during specific hours, similar to regular office hours.

At the beginning of each session, the teacher started by taking attendance. Students were supposed to send a text showing that they were present. Afterwards, the teacher explained the lesson through recording voice notes, sending videos explaining ideas on whiteboards, sharing links for YouTube material, and texting. The minimum length for voice notes was 3 minutes. When teaching algebraic and geometric rules and equations, the teacher wrote the rules on papers and/or scanned them from books and then sent them as images supported by voice notes to explain them. While recording voice notes, the students waited for the teacher to finish recording. For example, if a voice note was five minutes in length, they would have to wait five minutes for the teacher to send it. Although lessons were taught in English, and 
students were requested to communicate using it, participants in the group did not abide by the rule.

SMS language, internet acronyms, and Lebanese slang Arabic dominated the platform. Activities or group work collaborations were confined due to the lack of scale. Instead, students waited for after-class sessions to work on their group problem-solving sessions. They created subgroups where they shared their ideas and performed the assigned activities. When students had to report their assignments, they took images of their homework and sent them to the teacher separately.

\section{PARTICIPANT FEEDBACK}

Waiting between voice notes distracted the students and often led them to engage in other chats or activities. "This was very annoying and made me lose interest in continuing the session," said one student in the class. The weak internet services and the lack of speedy connections delayed receiving some messages sent during the lesson. "Some explanations were delivered after the session was over, and we had to figure out their context during the session" explained the student. The delay in connections affected the order of the voice messages sent. In some instances, heavy voice notes were delivered out of their order. This affected the understanding and comprehension of student's learned material.

Participation during sessions was limited. "It resulted in multiple people texting simultaneously, which created chaos and dispersed our attention" continued the student. Students who had further questions or wanted more clarifications on the given material were asked to keep their queries until the end of the session to avoid any interruptions during the explanation. The improper language of instruction made the learning session informal in nature. "Emojis were all over the place" exclaimed the student, as the teacher and the students used them, to elaborate on their intended messages.

Video calls on WhatsApp were not feasible. The slow internet connection and the lack of electricity were major reasons. Besides, a large number of participants, one teacher and 25 students, exceeded the limit set by WhatsApp for video calls. "I could only video call my friend after class to solve the problems together, but still the connection often was not helpful." elaborated the student on her video call experience.

Assessment of assignments was also hindered by the nature of the communication medium. "The teacher told us that she often forgot to correct some of the assignments because her WhatsApp was full of messages and she got lost" explained the student. "Indeed, the intermixing of private messages from my friends and family with messages from 25 students was challenging to handle at times" explained the teacher of the class. "Eventually, I had to buy a second phone to use for the class."

\section{CASE EVALUATION}

Assessment of the learning experience using the "Rubric eLearning Tool Evaluation" showed that WhatsApp, as a learning tool, was functional, accessible, and technically effective. Yet, it hindered the learning experience with the lack of social, teaching, and cognitive presence (Table 1). 
TABLE 1. Assessment of the learning experience of the Mathematics class using the Rubric for E-Learning Tool Evaluation.

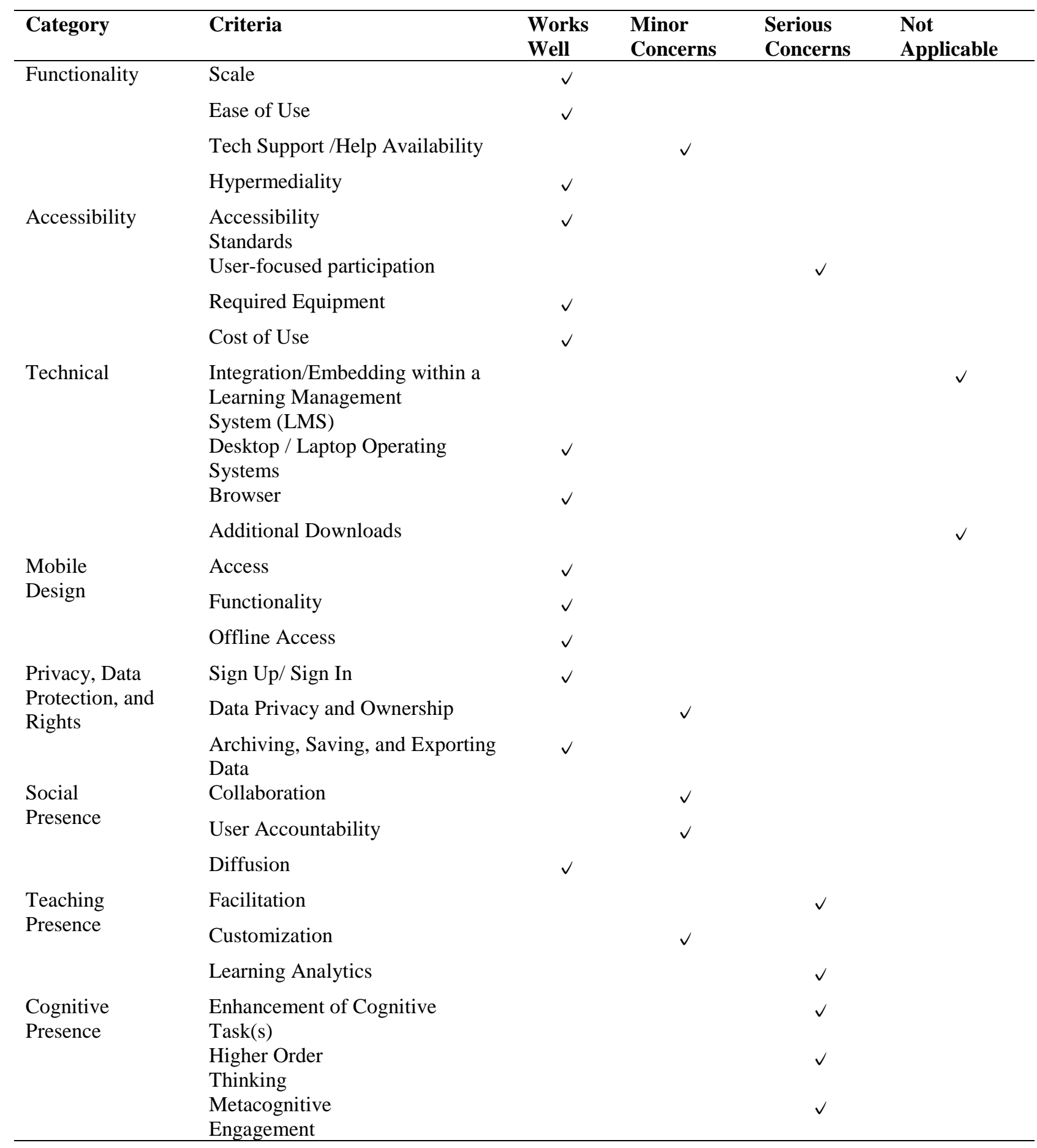

The WhatsApp learning experience met the functionality criterion, as students and teachers worked smoothly on the platform. The scale of the application succeeded in fitting the class's size. Participants were able to work on it without having a prior background or extensive ICT skills. Personalization was possible, as students could text their teacher and/or classmates in separate chats. Although technical support for students was missing, they were all familiar with the platform's features and did not experience any crash-related problems during sessions. 
Hypermediality was demonstrated by communicating via various mediums (voice notes, videos, texting, etc.).

WhatsApp was accessible through smartphones, which was available amongst students and/or their family members. Nevertheless, user-focused participation was not adequately addressed, as students with special needs, such as visual impairment, ADHD, or dyslexia, were not cared for on the platform. The application was free to download, and "WhatsApp bundles" offered by the telecommunication companies were affordable and reasonably priced.

WhatsApp was accessible through smartphones and desktop browsers, with no difference in functionality between the mobile and desktop versions. Besides, it did not require additional downloads. Yet, poor connection speeds and electric outages were problematic.

Participants lacked the live visual tools that form part of the learning experience on other e-learning platforms, such as Zoom, Microsoft Teams, and Cisco WebEx. During the offline mode, students were able to access preliminary information but could not engage or have real-time conversations.

WhatsApp required a registered account, with no need for logging in during each learning session. Conversations were protected by end-to-end encryption that does not allow data access to third parties. Yet, WhatsApp can share personal data with its parent company, Facebook (Page, 2021). In addition, students and teachers could save, delete, archive, and export the group discussions and materials.

Learning was both synchronous and asynchronous; however, students faced problems when tracking previously explained material for revision. The teacher could only hold the students accountable for what they text inside the group chat. The tool is the most common means of communication in Lebanon. Almost all learners were familiar with it and had basic technical knowledge on how to navigate it.

WhatsApp hindered facilitation. As a learning tool, it posed significant challenges on active management, the ability to monitor performance and participants' engagement, and the ability of the teacher to provide feedback. Overall, WhatsApp was customizable for the learning experience but in a limited manner, as it neither suited the classroom teaching context nor targeted the learning outcomes.

WhatsApp neither enhanced cognitive tasks nor instigated critical thinking, as the mode of communication facilitated distraction and disinterest. The waiting times between voice notes made it difficult for students to maintain their focus. In addition, the loss of the classroom setting made it difficult for the teacher to monitor the students visually and ensure that learning needs are being met. The metacognitive engagement was not present, as students could not track their performance, test their abilities and knowledge, or receive feedback.

\section{CASE ANALYSIS}

Our results demonstrated high functionality, accessibility, and technical effectiveness throughout the learning experience. Similarly, Nelson et al. examined the benefits of WhatsApp in blended mobile learning and found out that it helped students share knowledge and information easily through the texting feature of the application (2009). In addition, it enabled students to publish their work using WhatsApp groups (Nelson et al., 2009). Furthermore, 
WhatsApp has given the students an opportunity to learn regardless of the location and time (Seechaliao, 2014).

Our study showed that students were demotivated by the fact that teachers had sometimes forgotten to correct their assignments due to the high load of messages they receive. These results were supported by Deibert's study (2005), where students felt demotivated from the instructors' lack of response on the WhatsApp groups.

In our study, serious concerns were raised regarding teaching and cognitive presences during the learning experience on the platform. The chaos that erupts in the WhatsApp group if several students interact simultaneously limits interactive learning. The teacher's inability to monitor and direct the students' focus further exacerbated the problem. The nature of a mathematics class, which can be straightforward at times without the need for group discussions, also contributed to the limited cognitive presence on the platform.

The use of Emojis and Emoticons have been controversial. While some studies have reported that students found emoticons to be more interesting and fun when incorporated in the educational process (Suardika et al., 2020), our study showed that students found the overuse of emojis distracting and unprofessional. Other studies in the literature have shown other benefits of using WhatsApp as a learning tool. The platform increased the sense of community among group participants, which acts as a predictor of perceived learning (Trespalacios \& Perkins, 2016). The absence of face-to-face interactions also decreased the intimidation of the teacher (Suardika et al., 2020).

\section{CONCLUSION}

The COVID-19 pandemic forced lockdowns that severely affected the educational sector in countries that suffer from poor ICTs and MIL. In Lebanon, the pandemic exposed deficiencies in the preparedness of schools to shift to online learning. This resulted in the adoption of commonly used applications, such as WhatsApp, as a learning platform. Although WhatsApp, as an educational tool, was functional, accessible, and technically effective, it hindered the learning experience with the lack of social presence and the hindrance of teaching and cognitive presences. WhatsApp should not be used as a primary learning tool on its own, as it lacks essential components that define the learning experience. Governmental and non-governmental campaigns to address the learning crisis are essential. Public teaching sessions conducted through national broadcasting stations and other media channels are encouraged to teach the students how to operate on better e-learning platforms. Improving the telecommunication resources and electric infrastructures in the country is vital for technological civilization and proper integration of society in the $21^{\text {st }}$ century. Leveraging media and better communication strategies are also essential for crossing over to a knowledge society with strong ICT competencies and infrastructure. In addition, cultivating a media culture and enhancing media awareness promote the engagement of citizens in a knowledge society that is centered on human development and social empowerment.

DECLARATION OF INTEREST: None declared. 


\section{REFERENCES}

Anstey, L., \& Watson, G. (2018). A Rubric for Evaluating E-Learning Tools in Higher Education. Educause Review. https://er.educause.edu/articles/2018/9/a-rubric-forevaluating-e-learning-tools-in-higher-education

Aziza, M. (2021). Online Learning during Covid-19: What is the Most Effective Platform for Teaching and Learning Mathematics?. Edumatika: Jurnal Riset Pendidikan Matematika, 4(1), 166-178.

Başoğlu, E. B., \& Akdemir, O. (2010). A comparison of undergraduate students' English vocabulary learning: Using mobile phones and flashcards. Educational Technology, 9(3), 1-7.

Bindé, J. (2005). From the information society to knowledge societies. In Towards knowledge societies: UNESCO world report (pp. 27-36). Paris, France: United Nations Educational, Scientific and Cultural Organization.

Chen, C. H. (2008). Why do teachers not practice what they believe regarding technology integration? Journal of Educational Research, 102, 65-75.

Deibert, R. A. T. (2015). Student perceptions of blended mode learning: Supplementing asynchronous online learning with synchronous tools. Northcentral University.

Dempsey, M, and Burke, J. (2020) Covid-19 Practice in Primary Schools in Ireland Report: A Two-month Follow-up. Project Report. Maynooth University.

Dhawan, S. (2020). Online learning: A panacea in the time of COVID-19 crisis. Journal of Educational Technology Systems, 49(1), 5-22.

Etim, P. J., Udosen, I. N., \& Ema, I. B. (2016). Utilization of WhatsApp and students performance in geography in uyo educational zone, Akwa Ibom State. International Journal of Innovation and Research in Educational Sciences, 3(5), 2349-5219.

Frayha, N. (2009). The negative face of the Lebanese education system. Retrieved February 28, 2021, from http://lebanonrenaissance.org/assets/Uploads/0-The-negative-face-ofthe-Lebanese-education-system-by-Nmer-Frayha-2009.pdf.

Jafari, S., \& Chalak, A. (2016). The role of WhatsApp in teaching vocabulary to Iranian EFL learners at junior high school. English Language Teaching, 9(8), 85-92.

Keles, E. (2018). Use of Facebook for the community services practices course: Community of inquiry as a theoretical framework. Computers and Education, 116, 203-224.

Kim, H., Lee, M., \& Kim, M. (2014). Effects of mobile instant messaging on collaborative learning processes and outcomes: The case of South Korea. Journal of Educational Technology \& Society, 17(2), 31-42.

Kushwaha, P. S., \& Jhawar, N. (2018). Role of Whatsapp as a Teaching Aid to Enhance Learning Capabilities of Management Students. Ushus Journal of Business Management, 17(1), 43-52.

Lee, A. Y. (2013). Literacy and Competencies Required to Participate in Knowledge Societies. In Conceptual Relationship of Information Literacy and Media Literacy in Knowledge Societies (pp. 03-62). Paris, France: United Nations Educational, Scientific and Cultural Organization (UNESCO).

Masonbrink, A. R., \& Hurley, E. (2020). Advocating for children during the COVID-19 school closures. Pediatrics, 146(3), e20201440.

Mheidly, N., \& Fares, J. (2020c). Health communication in low-income countries: a 60-year bibliometric and thematic analysis. Journal of Education and Health Promotion, 9, 163.

Mheidly, N., \& Fares, J. (2020d). Health communication research in the Arab world: a bibliometric analysis. Integrated Healthcare Journal, 2, e000011.

Mheidly, N., Fares, M. Y., \& Fares, J. (2020b). Coping with stress and burnout associated with telecommunication and online learning. Frontiers in Public Health, 8, 574969. 
Mheidly, N., Fares, M. Y., Zalzale, H., \& Fares, J. (2020a). Effect of Face Masks on Interpersonal Communication During the COVID-19 Pandemic. Frontiers in Public Health, 8, 582191.

Nedungadi, P., Mulki, K., \& Raman, R. (2017). Improving educational outcomes \& reducing absenteeism at remote villages with mobile technology and WhatsAPP: Findings from rural India. Education and Information Technologies, 23(1), 113-127.

Nel, C., \& Marais, E. (2020). Preservice teachers use of WhatsApp to explain subject content to school children during the COVID-19 pandemic. International Journal of WorkIntegrated Learning, 21(5), 629.

Nelson, J., Christopher, A., \& Mims, C. (2009). TPACK and Mobile: Transformation of teaching and learning. TechTrends: Linking Research \& Practice to Improve Learning, 53(5), 80-87.

Nsabayezu, E., Iyamuremye, A., de Dieu Kwitonda, J., \& Mbonyiryivuze, A. (2020). Teachers' perceptions towards the utilization of WhatsApp in supporting teaching and learning of chemistry during COVID-19 pandemic in Rwandan secondary schools. African Journal of Educational Studies in Mathematics and Sciences, 16(2), 83-96.

Page, C. (2021). WhatsApp clarifies facebook DATA-SHARING as users flock to RIVAL SIGNAL. Forbes. Retrieved February 28, 2021, from https://www.forbes.com/sites/carlypage/2021/01/13/whatsapp-clarifies-facebookdata-sharing-as-users-flock-to-rival-signal/

Rahaded, U., Puspitasari, E., \& Hidayati, D. (2020). The Impact of whatsapp toward UAD undergraduate students' behavior in learning process. International Journal of Educational Management and Innovation, 1(1), 55-68.

Rambe, P., \& Bere, A. (2013). Using mobile instant messaging to leverage learner participation and transform pedagogy at a South African University of Technology. British Journal of Educational Technology, 44(4), 544-561.

Rouadi, N. E., \& Anouti, M. F. (2020). The online learning experiment in the intermediate and secondary schools in Lebanon during the coronavirus (COVID-19) crisis. Online learning, 7(7), 14466-14485.

Suardika, I. K., Suhartini, L., \& Pasassung, N. (2020). Using WhatsApp for Teaching a Course on the Education Profession: Presence, Community and Learning. International Journal of Mobile and Blended Learning, 12(1), 17-32.

Susanti, A., \& Tarmuji, A. (2016). Techniques of optimizing WhatsApp as an instructional tool for teaching EFL writing in Indonesian senior high schools. International Journal on Studies in English Language and Literature (IJSELL), 4(10), 26-31.

Trespalacios, J., \& Perkins, R. (2016). Sense of community, perceived learning, and achievement relationships in an online graduate course. Turkish Online Journal of Distance Education, 17(3), 31-49.

\author{
Nour Mheidly \\ Geisel García Graña \\ Sally Samy Tayie \\ Universitat Autònoma de Barcelona, Spain \\ nour.mheidly@e-campus.uab.cat
}

